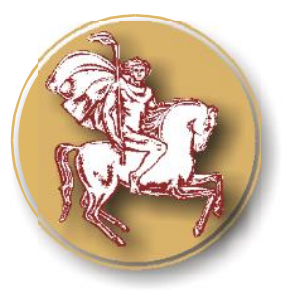

Trakia Journal of Sciences, No 1, pp 49-55, 2019

Copyright (C) 2019 Trakia University Available online at:

ISSN 1313-7050 (print) http://www.uni-sz.bg

ISSN 1313-3551 (online)

doi:10.15547/tjs.2019.01.008

Original Contribution

\title{
EGG QUALITY TRAITS IN WG, GG AND GL JAPANESE QUAIL POPULATIONS
}

\author{
H. Lukanov*, A. Genchev, P. Kolev
}

Faculty of Agriculture, Trakia University, Stara Zagora, Bulgaria

\begin{abstract}
The aim of the study was to evaluate egg quality traits in three heavy Japanese quail populations created and reared in the Poultry Breeding Unit of the Trakia University - Bulgaria, marked as WG, GG and GL. In the experiments, 160 female birds from populations WG and GG, and 96 birds from population GL were tested up to the 6th production month. The main egg quality traits were controlled. The highest average egg weight was registered in $\mathrm{WG}$ group and the lowest in GL group, $14.04 \pm 0.32 \mathrm{~g}$ and $12.79 \pm 0.29 \mathrm{~g}$ respectively $(\mathrm{p}<0.05)$. The highest average Shape index was observed in group GG $(78.31 \pm 0.53 \%)$, vs the lowest in WG quails $(77.55 \pm 0.62 \%)$. Albumen proportion is almost $2 / 3$ of egg mass, with average values from $57.14 \%$ in group WG to $59.90 \%$ in group GG. Yolk proportion was about $30 \%$, with smaller differences between the groups. The shell share from all tested groups comprised between 10.95 and $12.58 \%$ of egg weight. Average shell thickness was the greatest in eggs of WG quails $(223.53 \pm 5.52 \mu \mathrm{m})$, and the lowest - in GG quails $(216.91 \pm 6.83 \mu \mathrm{m})$. Egg quality traits were typical for the meat productive type of Japan quails.
\end{abstract}

Key words: domestic quail, meat type, egg yolk, egg albumen, IQU, HU.

\section{INTRODUCTION}

The main products obtained from domesticated Japanese quails (Coturnix japonica, Temminck $\&$ Schlegel, 1849) are eggs and meat. The global production of stocking quail eggs is based mainly of light layer and all-purpose quails. In some countries, including ours, quails from heavy types are also used for egg production due to the easier realisation of larger eggs and the lack of a constant need form breeder eggs. The incessantly increasing use of Japanese quails for egg production necessitate more information about eggs as produce. So far, there is no generally accepted and implemented standard, not a normative basis regulating minimum requirements to production, quality evaluation, packaging and storage of quail eggs. In most instance, regulations for the production, storage and sale of chicken eggs for direct consumption are

*Correspondence to: Hristo Lukanov, PhD; Department of Animal Science - monogastric and other animals, Faculty of Agriculture, Trakia University,6000 Stara Zagora, Bulgaria, e-mail: dr_lukanov@abv.bg,telephone:+359/898419751 mechanically transferred to this biological species (1). The egg production and egg quality, apart for stock production, is essential also for quail meat production and results from incubation of breeder eggs.

Three heavy-type Japanese quail populations were created and reared in the Poultry Breeding Unit of the Trakia University Bulgaria, designated as WG, GG and GL.

The aim of this study was to investigate the egg quality traits of the three heavy Japanese quail populations created and reared in the Poultry Breeding Unit of the Trakia University.

\section{MATERIAL AND METHODS}

The egg quality of three Japanese quail population created and reared in the Poultry Breeding Unit of the Trakia University was evaluated. They comprised two heavy populations with wild and golden plumage, designated as WG and GG and one dualpurpose population with cinnamon plumage GL. In the experiments, 160 female birds from populations WG and GG, and 96 birds from 
population GL were used. At 35 days of age, the birds were allotted in 10 subgroups with 16 birds each from WG and GG types, and 6 subgroups with 16 GL quails. The birds were reared in batteries in compliance with all hygiene requirements for the species and production type.

The quails were reared under constant 16-hour light day from 35 days of age to the end of the 6 th production month.

Feeding was uniform throughout the experiment with the following composition of the compound feed: ME: $11.5 \mathrm{MJ} / \mathrm{kg}$; CP: $19.5 \%$; lysine: $1.0 \%$; methionine+cysteine: $0.75 \%$; calcium: $2.8 \%$; available phosphorus: $0.45 \%$, and optimum levels of vitamins and minerals.

The evaluation of egg quality was performed from the age of lay to the end of the 6th production month. In the middle of each production month, all eggs laid for 48 hours from the three populations (WG, GG and GL) were collected for egg quality analysis.

The weight of eggs and weights of its parts albumen, yolk and eggshell with membranes were determined on a CB 2000 balance with precision of $0.01 \mathrm{~g}$.

The big and small diameters of eggs were determined with Vernier caliper with precision of $0.05 \mathrm{~mm}$. Diameters of the yolk and albumen were measured after breaking the eggs on a horizontal smooth surface. Yolk and albumen heights at the yolk/albumen boundary was determined with a tripod vertical Ames micrometer with precision of $0.01 \mathrm{~mm}$.

Shell thickness with membranes in the equatorial region, and at blunt and sharp edges was measured with a micrometer with precision of $0.01 \mathrm{~mm}$ and average eggshell thickness (including outer shell membrane) was calculated.

External egg dimensions served for calculation of the shape index (\%) as SI=d/D*100 [1], where $\mathrm{d}-$ small diameter of the egg, $\mathrm{mm}, \mathrm{D}-$ big diameter of the egg, (2);

The shell surface area $\left(\mathrm{cm}^{2}\right)$ was obtained using the formula: $\mathrm{S}=4.835^{*} \mathrm{~W}^{0.662}$ [2], where $\mathrm{W}$ - egg weight (3).

For egg albumen quality evaluation, the following traits were calculated:

Albumen index: $\mathrm{AI}=\mathrm{h} /(0.5 *(\mathrm{~d}+\mathrm{D})) * 100$ [3],
LUKANOV H., et al.

where $\mathrm{h}$ - thick albumen height, $\mathrm{d}-$ small diameter of the thick albumen, and D - big diameter of the thick albumen, (2);

Haugh units:

$H U=100 * \log \left(h+7.57-1.7 * W^{0.37}\right)[4]$,

where: $\mathrm{h}$ - thick albumen height, and $\mathrm{W}-\mathrm{egg}$ weight, g (4);

Internal quality units of the albumen:

$I Q U=100 * \log \left(h+4.18-0.8989 * W^{0.6674}\right)$ [5],

where $\mathrm{h}$ - thick albumen height; W - egg weight (5).

Egg yolk quality was determined through the yolk index: YI $=h / D^{*} 100[6]$, where $h-$ yolk height, D - yolk diameter, $\mathrm{mm}$ (2);

Eggshell colour was determined visually by comparison with the DSM yolkfan.

All data were processed with statistical software Statistica 13.0 (Statistica for Windows; Stat - Soft, 2015). Mean (x), standard error of mean (SEM) and coefficient of variation $(\mathrm{CV}, \%)$ values were calculated for each group. The differences considered statistically significant at $\mathrm{p}<0.05$, using Student's t-test, if the data were normally distributed.

\section{RESULTS AND DISCUSSION}

Table 1 summarises the data for egg exterior traits - average weight, big and small diameter, shape index. The largest eggs were produced by the WG group and the smallest - by the GL group. An interesting fact was observed: differences in egg size were mostly due to the big diameter (D), while the differences in small diameter of eggs (d) in the three groups were not significant. The average egg weight corresponded to heavy-type quails (1, 6-8). The highest average egg weight was registered in WG eggs $(14.04 \pm 0.32 \mathrm{~g})$, followed by GG $(13.65 \pm 0.27 \mathrm{~g})$ and GL $(12.79 \pm 0.29 \mathrm{~g})$ eggs. The difference between average egg weights of the lightest population (GL) and the heaviest one (WG) was significant $(\mathrm{p}<0.05)$. Lower egg weights in meat-type quails were also affirmed $(6,8-10)$. Shape index (SI, \%) is an important species-, breed-, line- and individually-related trait influencing egg strength, its fitting into standard packages and for hatching eggs - its hatchability. In this experiment, so statistically significant differences were found out in shape index (SI) values in the three groups. Average monthly values of the populations were similar - between $79.91 \pm 0.58 \%$ and $75.19 \pm 2.21 \%$. The values were slightly higher than those considered as ideal in chicken eggs, expressed 
in a more rounded shape of quail eggs than the standard. Another feature of quail eggs is that they are more pointed than those of chickens, but this could not be seen from SI values. The highest average SI was observed in group GG
LUKANOV H., et al $(78.31 \pm 0.53 \%)$, vs the lowest in WG quails $(77.55 \pm 0.62 \%)$. Our data about shape index agreed with those of other researchers having assessed quail egg quality $(8,11-15)$.

Table 1. Average egg exterior traits.

\begin{tabular}{|c|c|c|c|c|}
\hline parameter & group & WG & GG & GL \\
\hline \multirow{3}{*}{$\begin{array}{l}\text { average egg weight, } \\
\mathrm{g}\end{array}$} & $\mathrm{x}$ & 14.04 & 13.65 & 12.79 \\
\hline & SEM & 0.39 & 0.32 & 0.35 \\
\hline & significance & $1: 3^{*}$ & & \\
\hline \multirow{3}{*}{$\mathrm{D}, \mathrm{mm}$} & $\mathrm{x}$ & 36.39 & 34.73 & 33.82 \\
\hline & SEM & 1.86 & 0.29 & 0.28 \\
\hline & significance & $2: 3^{*}$ & & \\
\hline \multirow{3}{*}{$\mathrm{d}, \mathrm{mm}$} & $\mathrm{x}$ & 27.14 & 27.17 & 26.37 \\
\hline & SEM & 0.20 & 0.20 & 0.19 \\
\hline & significance & $1: 3^{* *} ; 2: 3^{* *}$ & & \\
\hline \multirow{3}{*}{ SI, \% } & $\mathrm{x}$ & 77.55 & 78.31 & 78.11 \\
\hline & SEM & 0.62 & 0.53 & 0.51 \\
\hline & significance & NS & & \\
\hline
\end{tabular}

From the surface inward, the egg consists of a shell with membranes, albumen and yolk. The last two layers are valuable nutrients whereas the shell and membrane protect them from adverse environmental influence. The results make clear that there were no between-group difference with respect to the distribution of egg parts (Figure 1). This could be explained by the relatively constant intra-species values of the trait, evolutionally associated to species reproduction. The share of valuable quail egg parts in the three groups varied from 87.42 and $89.05 \%$, and quail eggs have higher yolk content than chicken eggs $(10,16)$. Albumen proportion is almost $2 / 3$ of egg mass, with average values from $57.14 \%$ in group WG to $59.90 \%$ in group GG. Our data in the three groups are comparable to results from similar research studies $(10,13,14)$. In some studies higher albumen percentage in quail eggs were affirmed (18, 19). Taha (20) reported significantly lower albumen and yolk shares vs the total egg; from $51.62 \pm 0.71 \%$ and $55.29 \pm 2.12 \%$ depending on the eggshell colour. Yolk proportion was about 30\%, with smaller differences (by 3.73\%) between the groups compared to those for albumen and eggshell. Similar figures could be found in the works of other researchers $(10,13,16,17)$. Wilkanowska and Kokoszyński (19) reported similar but lower values than ours. Higher values for yolk were also demonstrated (14, $15,20)$. The shell comprised between 10.95 and $12.58 \%$ of egg weight on the average, with highest between-group variation of $12.93 \%$, compared to other egg parts. Our data are similar to those of Zita et al. (13) and Sari et al. (14). Taha (20) reported higher relative proportion in quail eggs with different shell colour. Wilkanowska and Kokoszyński (19) reported lower eggshell share that declined with age in Pharaoh quails. Hanusová et al. (10) established a relative share of shell + membranes of $9.128 \pm 0.022 \%$ and 9.200 $\pm 0.036 \%$ in two Japanese quail population. Again, lower values of the trait in quail eggs were affirmed by Pizzolante et al. (18) and Alaşahan et al. (15).

Table 2 provides data concerning albumen and yolk quality. Albumen quality traits (albumen index, Haugh units and Internal quality units) did not exhibit large differences between the three populations. The comparison of traits confirmed that ranking observed for AI (\%) was preserved also for $\mathrm{HU}$ and IQU. The 
highest albumen egg quality was found out in Gl quails with $11.61 \pm 0.42 \%$ for AI, $90.10 \pm 1.04$ for $\mathrm{HU}$ and $59.55 \pm 2.40$ for IQU. The lowest values were registered in GG quails $(10.32 \pm 0.31 \%, 87.33 \pm 0.71$ and $52.20 \pm 1.75$ respectively; $\mathrm{p}<0.05)$. The $\mathrm{WG}$ population occupied an intermediate position with respect to egg albumen quality. Some authors reported comparable albumen index results in Japanese quails $(10,13,15,21)$. Lower values were obtained by Sari et al. (14) and Hrnčár et al. (8). Compared to chicken stock eggs, those of quails had considerably lower AI (13). Haugh units of Japanese quail eggs with close values were demonstrated by Sari et al. (14), Hrnčár
LUKANOV H., et al. et al. (8), Alaşahan et al. (15) and Hanusová et al. (10), and lower values: by Zita et al. (13). The analysis of the three traits of albumen quality, the broadest range of average values in the three populations were found out for internal quality units of albumen (IQU) - 7.36. The similar trait - HU, used in larger eggs, the differences were twice smaller. This confirmed the better accuracy of IQU in small-size eggs (5). Comparable IQU data were communicated by Genchev and Kabakchiev (9) and Genchev (22). Substantially lower values were reported by Erensayin and Camci (23) and Fouladi et al. (24), on the contrary those of Mohapatra et al. (25) were slightly higher than ours.

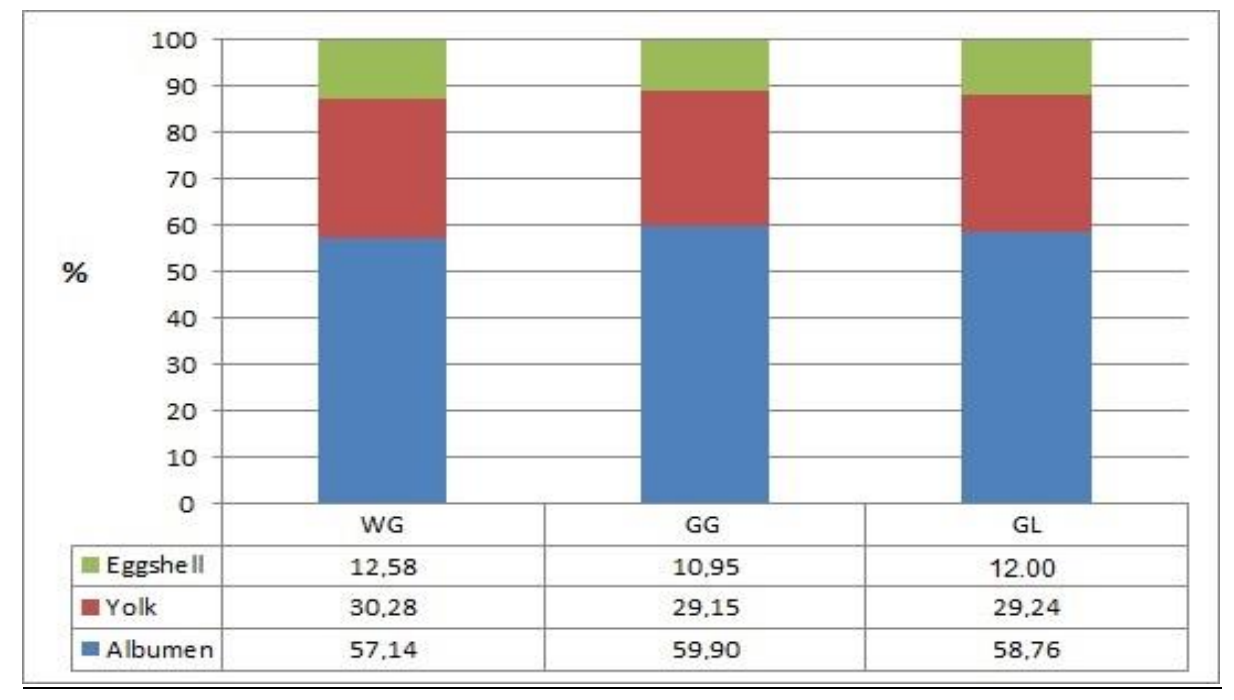

Figure 1. Proportions of egg parts.

Table 2. Average internal egg quality traits.

\begin{tabular}{|c|c|c|c|c|}
\hline parameter & group & WG & GG & GL \\
\hline \multirow{3}{*}{ AI, $\%$} & $\mathrm{x}$ & 11.19 & 10.32 & 11.61 \\
\hline & SEM & 0.39 & 0.31 & 0.42 \\
\hline & significance & $2: 3^{*}$ & & \\
\hline \multirow{3}{*}{$\mathrm{HU}$} & $\mathrm{x}$ & 88.71 & 87.33 & 90.10 \\
\hline & SEM & 1.03 & 0.71 & 1.04 \\
\hline & significance & $2: 3^{*}$ & & \\
\hline \multirow{3}{*}{ IQU } & $\mathrm{x}$ & 54.25 & 52.20 & 59.55 \\
\hline & SEM & 2.79 & 1.75 & 2.40 \\
\hline & significance & $2: 3^{*}$ & & \\
\hline \multirow{3}{*}{ YI, \% } & $\mathrm{x}$ & 48.95 & 47.07 & 48.13 \\
\hline & SEM & 0.54 & 1.10 & 1.13 \\
\hline & significance & NS & & \\
\hline \multirow{3}{*}{$\begin{array}{l}\text { Yolk colour, } \\
\text { DSM yolkfan }\end{array}$} & $\mathrm{x}$ & 4.66 & 4.42 & 4.25 \\
\hline & SEM & 0.18 & 0.13 & 0.19 \\
\hline & significance & NS & & \\
\hline
\end{tabular}

Yolk index (YI, \%) in the three groups varied within a narrow range from $48.95 \pm 0.54 \%$ in
WG to $47.07 \pm 1.10 \%$ in $\quad$ GG $\quad(p>0.05)$. Analogous results were reported for this trait in 
several studies $(9,13,16)$. Significantly higher yolk index values were obtained by Hanusová et al. (10) in two Japanese quail population while a number of authors - lower YI values $(8,14,15,19,24)$. The trait related rather to consumers' attitudes than to egg quality is yolk colour, which also showed insignificant differences in the three groups. This could be anticipated as yolk colour depends directly on dietary carotenoids which are the same for all groups. Values corresponded to pale yellow yolk colour - from $4.25 \pm 0.19$ in GL to $4.66 \pm 0.18$ in WG by the DSM scale. The utilisation of feed with similar nutritional content but various components causes serious variations in yolk colour in the different literature sources.

Table 3 presents data related to eggshell quality. Average shell thickness was the greatest in eggs of WG quails $(223.53 \pm 5.52 \mu \mathrm{m})$, and the lowest - in GG quails $(216.91 \pm 6.83 \mu \mathrm{m})$. The differences between the groups were very low $(p>0.05)$. Detailed information by months of production revealed the highest thickness during
LUKANOV H., et al the 2nd and 3rd production month in all groups, corresponding to the highest egg weight (Figure 2). The lowest average monthly shell thickness was found out in GL population during the 5th month of the cycle $(186.00 \pm 3.28 \mu \mathrm{m})$, and the highest: in group GL during the 3rd month of production $(240.63 \pm 2.69 \mu \mathrm{m})$. According to some authors, shell thickness in quail eggs decreased with age $(19,26)$, which was observed partly by us. Wilkanowska and Kokoszyński (19) and Hrnčár et al. (8) reported comparable shell thickness values. In some research average eggshell thickness was higher $(10,27)$, while other data demonstrated lower values of this traits in Japanese quail eggs $(14,28)$, most probably from the light all-purpose type.

Shell surface area ranged also within a narrow range in all groups $\left(26.08 \pm 0.49 \mathrm{~cm}^{2}\right.$ in GL group to $27.67 \pm 0.61 \mathrm{~cm}^{2} ; \mathrm{p}<0.05$ ), following the same pattern as egg weight. Due to the smaller egg size during the first month of production, surface areas were lower in all groups as compared to the other months from the production cycle.

Table 3. Average eggshell quality and shell surface area.

\begin{tabular}{lllll}
\hline parameter & group & WG & GG & GL \\
\hline \multirow{3}{*}{ ST, $\mu \mathrm{m}$} & $\mathrm{x}$ & 223.53 & 216.91 & 217.16 \\
& SEM & 5.52 & 6.83 & 9.01 \\
& significance & NS & & \\
$\mathrm{S}, \mathrm{cm}^{2}$ & $\mathrm{x}$ & 27.67 & 26.86 & 26.08 \\
& SEM & 0.61 & 0.90 & 0.49 \\
\hline
\end{tabular}

$* \mathrm{p}<0.05 ; * * \mathrm{p}<0.01 ; * * * \mathrm{p}<0.001 ; \mathrm{NS}-$ Non Significant

$\mathrm{ST}$ - shell thickness; $\mathrm{S}$ - shell surface area.

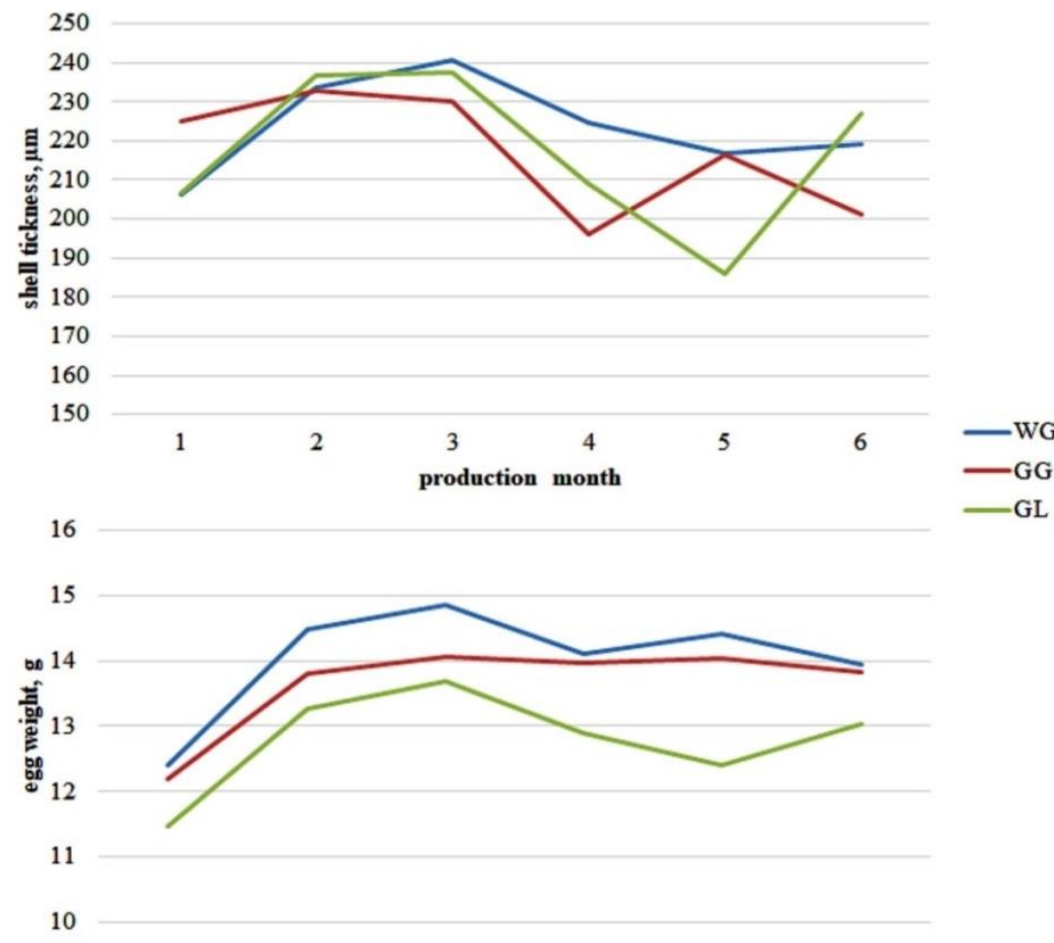

Figure 2. Comparisson of monthly eggshell thickness and egg weight. 


\section{CONCLUSION}

Egg quality traits were typical for the productive type of evaluated groups. The average egg weight corresponded to heavytype quails. The largest eggs were produced by the WG group and the smallest - by the GL group $(\mathrm{p}<0.05)$. The Shape index $(\%)$ values were slightly higher than those considered as ideal in chicken eggs, expressed in a more rounded and pointed shape of quail eggs. The share of valuable quail egg parts (yolk and albumen) in the three groups varied from 87.42 and $89.05 \%$. Albumen quality traits (AI, HU and IQU) did not exhibit large differences between the three populations. Average shell thickness was the greatest in eggs of WG quails and the lowest - in GG quails, with very low differences between the groups $(\mathrm{p}>0.05)$.

\section{REFERENCES}

1. Genchev, A. and Lukanov, H., Padpadakovadstvo. Stara Zagora, 2018, In Print. (In Bulgarian)

2. Romanoff, A.L. and Romanoff, A.J., Avian egg. John Wiley \& Sons Inc; First Edition edition, 1949.

3. Paganelli, C.V., Olszowka, A. and Ar, A., The avian eggs: Surface area, volume and density. Condor, 76: 319-325, 1974.

4. Haugh, R.R., The Huagh unit for measuring egg quality. U.S. Egg Poultry Magazine, 43:552-555/572-573, 1937.

5. Kondaiah, N., Panda, B. and Singhal, R.A., Internal egg quality measure for quail eggs. Indian Journal of Animal Sciences, 53: 1261-1264, 1983.

6. Mori, C., Garcia, E.A., Pavan, A.C., Piccinin, A., Scherer, M.R. and Pizzolante, C.C., Desempenho e qualidade dos ovos de codorna de quatro grupos genéticos. Revista Brasileira de Zootecnia, 34: 864-869, 2005.

7. Santos, T.C., Murakami, A.E., Fanhani, J.C. and Oliveira, C.A.L., Production and reproduction of egg- and meat-type quails reared in different group sizes. Brazilian Journal of Poultry Science, 13(1): 9-14, 2011.

8. Hrnčár, C., Hanusová, E., Hanus, A. and Bujko, J., Effect of genotype on egg quality characteristics of Japanese quail (Coturnix Japonica). Slovak Journal of Animal Science, 47 (1): 6-11, 2014.

9. Genchev, A. and Kabakchiev, M., Egg productivity and egg quality estimation and evaluation of two breeds of Japanese quails (Coturnix japonica). Agricultural Science and Technology, 1: 8-12, 2009.
LUKANOV H., et al.

10.Hanusová, E., Hrnčár, C., Hanus, A. and Oravcová, M., Egg traits in Japanese quails. Acta Fytotechnica et Zootechnica, 19 (Special Issue): 62-67, 2016.

11.Panda, B. and Singh, R.P., Development in processing quail meat and eggs. World's Poultry Science Journal, 46 (3): 219-234, 1990.

12.Polat, R., Tarhan, S., Cetin, M. and Atay, U., Mechanical behaviour under compression loading and some physical parameters of Japanese quail (Coturnix coturnix japonica) eggs. Czech Journal of Animal Science, 52 (2): 50-56, 2007.

13.Zita, L., Ledvinka, Z., Tumova, E. and Klesalova, L., Technological quality of eggs in relation to the age of laying hens and Japanese quails. Revista Brasileira de Zootecnia, 41 (9): 2079-2084, 2012.

14.Sari, M., Işık, S., Önk, K., Tilki, M. and Kirmızıbayrak, T., Effects of layer age and different plumage colors on external and internal egg quality characteristics in Japanese quails (Coturnix coturnix japonica). Archiv fur Geflugelkunde, 76: 254- 258, 2012.

15.Alaşahan, S., Akpınar, G.C., Canoğulları, S. and Baylan, M., Determination of some external and internal quality traits of Japanese quail (Coturnix coturnix japonica) eggs on basis of eggshell colour and spot colour. Eurasian Journal of Veterinary Sciences, 31 (4): 235-241, 2015.

16.Zita, L., Ledvinka, Z. and Klesalová, L., The effect of the age of Japanese quails on certain egg quality traits and their relationships. Veterinarski Archiv, 83: 223232, 2013.

17.Nowaczewski, S., Kontecka, H., Rosiński, A., Koberling, S. and Koronowski, P., Egg quality of Japanese quail depends on layer age and storage time. Folia Biologica, 58: 201-207, 2010.

18.Pizzolante, C.C., Faltarone, A.B.G., Garcia, E.A., Saldanha, E.S.P.B., Deodato, A.P., Sherer, M.R., Mendes, A.A., Mori, C., Pelicia, K., Production performance and egg quality of quails (Coturnix japonica) during several periods of the day. Brazilian Journal of Poultry Science, 8(3): 149-152, 2006.

19.Wilkanowska, A. and Kokoszyński, D., Layer age and quality of Pharaoh quail eggs. Journal of Central European Agriculture, 13(1): 10-21, 2012.

20.Taha, A.E., Analyzing of quail eggs hatchability, quality, embryonic mortality 
and malpositions in relation to their shell colors. Online Journal of Animal and Feed Research, 1(6): 267-273, 2011.

21.Tabeekh, M.A.S.A., Evaluation of some external and internal egg quality traits of quails reared in Basrah City. Basrah Journal of Veterinary Research, 10 (2): 7884, 2011.

22.Genchev, A., Quality and composition of Japanese quail eggs (Coturnix japonica). Trakia Journal of Sciences, 10: 91-101, 2012.

23.Erensayin, C. and Camci, O., Effects of the oviposition time on egg quality in quails. Archiv fur Geflugelkunde, 66 (6): 283 284, 2002.

24.Fouladi, P.I., Ebrahimnezhad, Y.I., Aghdam Shahryar, H.I., Maheri, N.I. and Ahmadzadeh, A.I., Effects of organic acids supplement on performance, egg traits, blood serum biochemical parameters and gut microflora in female Japanese quail (Coturnix coturnix japonica). Brazilian
LUKANOV H., et al Journal of Poultry Science, 20 (1): 133144, 2018.

25.Mohapatra, N., Kataria, J.M., Chakraborty, S. and Dhama, K., Egg Drop Syndrome-76 (EDS-76) in Japanese Quails (Coturnix coturnix japonica): An Experimental Study Revealing Pathology, Effect on Egg Production/Quality and Immune Responses. Pakistan Journal of Biological Sciences, 17: 821-828, 2014.

26. Yannakopoulos, A.L. and Tserveni-Gousi, A.S., Quality characteristics of quail eggs. British Poultry Science, 27: 171-176, 1986.

27.Ergun, O.F. and Yamak, U.S., The effect of eggshell thickness on hatchability of quail eggs. Veterinary World, 10(9): 1114-1117, 2017.

28.Nepomuceno, R.C., Watanabe, P.H., Freitas, E.R., Cruz, C.E., Braga, P., Maria, S.M. and Sousa, M.L., Quality of quail eggs at different times of storage. Ciência Animal Brasileira, 15(4): 409-413, 2014. 